\title{
Relating climate change signals and physiographic catchment properties to clustered hydrological response types
}

\author{
N. Köplin ${ }^{1,2}$, B. Schädler ${ }^{1,2}$, D. Viviroli ${ }^{1,2}$, and R. Weingartner ${ }^{1,2}$ \\ ${ }^{1}$ Institute of Geography, University of Bern, Switzerland \\ ${ }^{2}$ Oeschger Centre for Climate Change Research, University of Bern, Switzerland
}

Correspondence to: N. Köplin (nina.koeplin@web.de)

Received: 27 February 2012 - Published in Hydrol. Earth Syst. Sci. Discuss.: 12 March 2012

Revised: 16 May 2012 - Accepted: 19 June 2012 - Published: 23 July 2012

\begin{abstract}
We propose an approach to reduce a comprehensive set of 186 mesoscale catchments in Switzerland to fewer response types to climate change and to name sensitive regions as well as catchment characteristics that govern hydrological change. We classified the hydrological responses of our study catchments through an agglomerativehierarchical cluster analysis, and we related the dominant explanatory variables, i.e. the determining catchment properties and climate change signals, to the catchments' hydrological responses by means of redundancy analysis. All clusters except for one exhibit clearly decreasing summer runoff and increasing winter runoff. This seasonal shift was observed for the near future period (2025-2046) but is particularly obvious in the far future period (2074-2095). Within a certain elevation range (between 1000 and $2500 \mathrm{~m}$ a.s.l.), the hydrological change is basically a function of elevation, because the latter governs the dominant hydro-climatological processes associated with temperature, e.g. the ratio of liquid to solid precipitation and snow melt processes. For catchments below the stated range, hydrological change is mainly a function of precipitation change, which is not as pronounced as the temperature signal is. Future impact studies in Switzerland can be conducted on a reduced sample of catchments representing the sensitive regions or covering a range of altitudes.
\end{abstract}

\section{Introduction}

The latest climate scenarios for Switzerland project a summer mean temperature increase of $3.7-4.1{ }^{\circ} \mathrm{C}$ and a summer mean precipitation decrease of $18-24 \%$ for the A1B emission scenario and the late 21st century $(\mathrm{CH} 2011,2011)$.
These changes in climate will inevitably induce changes in Switzerland's hydrology because the hydrological cycle is closely connected to the climate system. This was demonstrated in numerous studies covering a range of different foci and scales, from rather detailed and local-scale case studies (e.g. Finger et al., 2012; Graham et al., 2007; Hänggi, 2011; Huss et al., 2008; Jasper et al., 2004; Kunstmann et al., 2004; Schaefli et al., 2007) to broader analyses at the regional or continental scale (e.g. Bergström et al., 2001; Christensen and Lettenmaier, 2007; Dankers and Middelkoop, 2008; Hamlet, 2011).

With the "Bali Action Plan", the United Nations Framework Convention on Climate Change (UNFCCC) identified the need to integrate adaptation actions into sectoral and national planning (UNFCCC, 2008). Switzerland, as a party to the Convention, adjusted its climate policy according to the UNFCCC obligations and formulated a Swiss adaption strategy, where water resources management was identified as one of nine sectors specifically affected by climate change (FOEN, 2010). Among others, the adaptation strategy includes frequent updates of climate-impact studies according to the most recent climate scenarios. The latest of those impact studies is the joint research project "Climate Change and Hydrology in Switzerland" (CCHydro; Volken, 2010), which the study presented here is part of.

A comprehensive hydrological climate-impact study, however, that accounts for all sources of uncertainties is an utmost demanding task in terms of computational power and time. Ideally, it would involve a series of different greenhouse gas emission scenarios forcing different general circulation models (GCMs), into which different regional climate models (RCMs) are nested. The regional climate models, in 
turn, would be downscaled with different downscaling procedures to drive a number of hydrological models, each having a series of different parameter sets and being run for different catchment types. This extensive modelling setup would allow a complete integration and quantification of all possible sources of uncertainty along the impact-modelling chain. The associated heavy workload, however, is far beyond the means and would even increase with forthcoming generations of climate scenarios that are likely to be available in a higher spatial and temporal resolution.

Obviously, it is impossible to execute this idealized impact-modelling chain whenever a new generation of climate scenarios is available, and ways to simplify the procedure are indispensable. Therefore, the aim of this study is to ease the multi-dimensional task of impact modelling by reducing the catchments to a few distinct response types and assessing their specific climate-sensitivity, for example. This facilitates to conduct future impact studies only in the most affected regions, which eases the workload to a great extent.

To achieve a dimension reduction, we first classify a comprehensive set of catchments based on their hydrological responses to climate change to answer our first research question: (1) are there certain types of hydrological responses, i.e. can the catchments be grouped into fewer response types? We assume a differentiation and, therefore, a possible grouping of the catchments due to their hydrological responses, because Wagener et al. (2007) identified the response behaviour as the "[...] main differentiating metric between catchments". In a second step, the resulting response types are analysed to find out (2) which response types are specifically sensitive to changes in climate. Finally, we assess the relative impact of climate change signals and catchment properties on the hydrological response to test (3) if there are general causal relationships between hydrological responses to climate change and catchment properties. We want to assess this relative impact of climate and catchment properties, because the climate change signal might not be the only factor determining the hydrological response to climate change. Sawicz et al. (2011) found, for example, "[...] that soil properties will modify the impacts of climate change on hydrologic regimes, which means that changes in precipitation and temperature will not impact the streamflow response equally". If there are such modifying catchment characteristics like soil properties or other physiographic signatures in our study region, then the entity of catchments to be analysed can be reduced to a sample that is representative for the determining properties. One approach to relate catchment characteristics to hydrological response is to classify catchments according to their physiographic properties and compare them to the classification of the hydro-climatological response (see e.g. Ley et al., 2011). Here, we relate the hydrological response to both the catchment properties and the climate change signals by means of redundancy analysis, a constrained ordination method widely used in vegetation ecol- ogy that has been demonstrated to be effectively applicable to hydrologic data, too (Ali et al., 2011).

Based on the latest climate scenario data for Switzerland, we apply the proposed procedure to an extensive set of 186 mesoscale catchments that represent the variety of Switzerland's hydrological systems. With a view on practical application, the reduction of the variety of hydrological responses to the most important types will facilitate identification of regions where adaptation measures should be applied to with priority.

\section{Study area and data}

We studied 186 catchments in Switzerland (study catchments, Fig. 1) that cover an area of $63 \%\left(25865 \mathrm{~km}^{2}\right)$ of the country. Switzerland has a variety of different landscape types, from the Jura limestone range in the northwest over the rather flat Swiss Plateau and the high alpine area, which constitute a continental drainage divide, to the inner alpine valleys and the southern alpine region with their distinct climates. Because of this heterogeneous landscape structure, a range of different catchment types evolved, which is reflected in the catchments' mean elevations, for example, ranging from 438 to $3024 \mathrm{~m}$ a.s.l. The study catchments have an average area of approximately $250 \mathrm{~km}^{2}$.

We used hourly discharge measurements for the period from 1983 to 2005 (FOEN, 2008) to calibrate and validate our hydrological model for 163 catchments (calibrated catchments in Fig. 1). Discharge data are available for more catchments than those calibrated here, but in the alpine areas, for example, hydropower production biases the discharge measurements, which is why we could not use these data for model calibration.

Meteorological data are available in hourly to daily resolution, depending on the type of meteorological station (Fig. 1). For the 77 stations of the automatic meteorological network, the data are available in $1 \mathrm{~h}$ resolution, while 84 climate stations provide data two or three times a day, and 668 precipitation gauges measure with a daily resolution (cf. Fig. 1; MeteoSwiss, 2008). Model forcing is mainly based on the 77 meteorological stations with hourly data and complemented by other stations with data at lower temporal resolutions.

\subsection{Model data}

We used the hydrological modelling system PREVAH (Precipitation-Runoff-EVApotranspiration-Hydrotope-based model; Viviroli et al., 2009a) that is semi-distributed because it relies on the concept of hydrological response units (HRUs) and that is process-oriented as it incorporates, for example, combined temperature-radiation modules for snow and ice melt. In this study, PREVAH is run on the basis of hourly meteorological input (temperature, precipitation, relative humidity, wind speed, global radiation and sunshine 


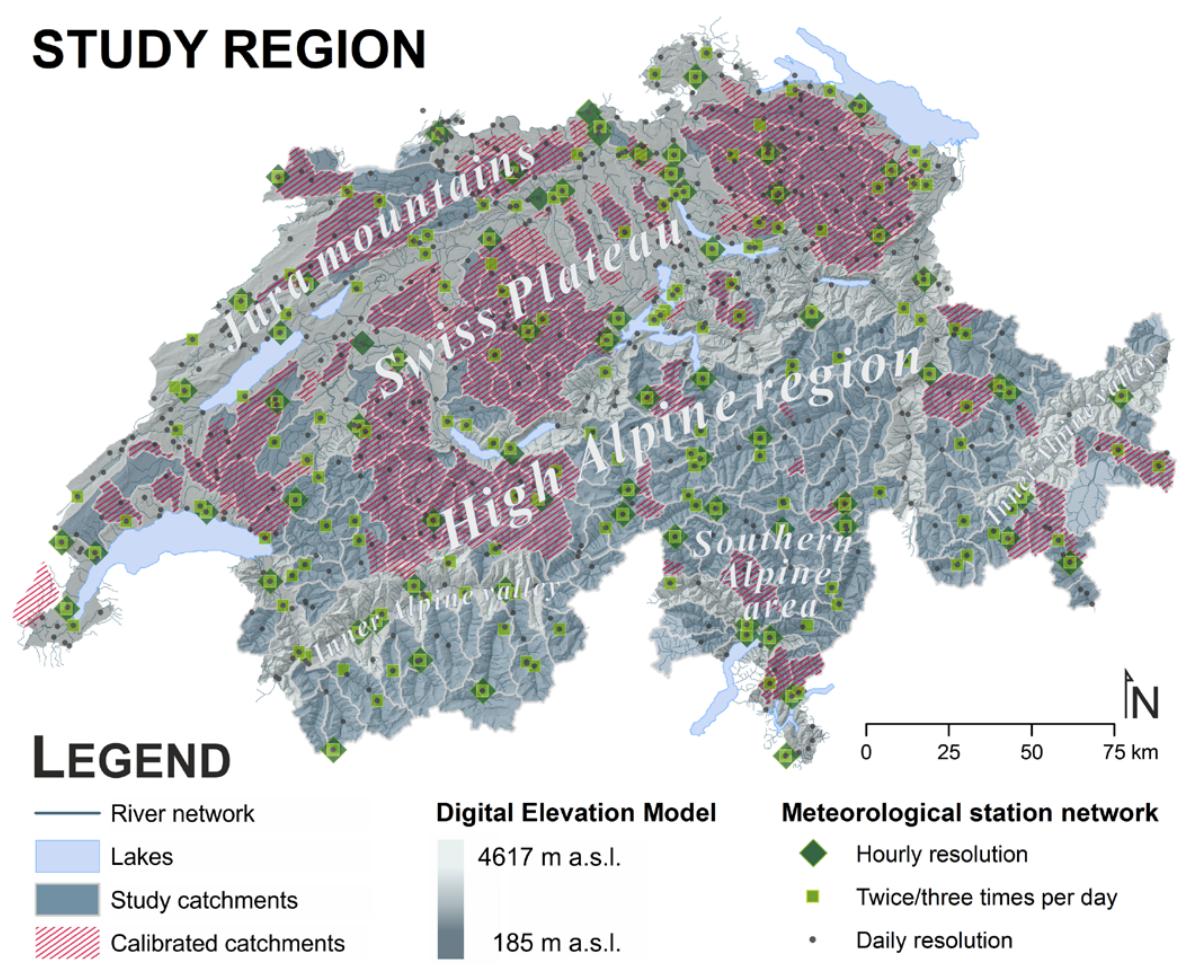

Fig. 1. Overview of the study region. Note that the study catchments (white borders) and the calibrated catchments are partly superimposed. The calibrated catchments are located within the red hatched areas, but their watershed boundaries are not delineated to enhance legibility.

duration) and at a spatial resolution of $500 \times 500 \mathrm{~m}^{2}$. We extended an existing set of 140 calibrated northern alpine catchments (Viviroli et al., 2009b) to southern alpine catchments (Köplin et al., 2010) following the calibration procedure designed by Viviroli et al. (2009b). Thus, we obtained a comprehensive set of 163 calibrated catchments representing the variety of catchment types in Switzerland. The evaluation of the calibration results for the northern and the southern alpine catchments is described in detail in Viviroli et al. (2009b) and in Köplin et al. (2010), respectively.

The 163 calibrated model parameter sets were used to regionalize runoff simulations for ungauged catchments, subsequently. For this, we used a regionalization scheme by Viviroli et al. (2009c) developed for flood estimation in small- to mesoscale catchments in Switzerland (Viviroli and Weingartner, 2011). The scheme combines three different regionalization methods (nearest neighbours, kriging and regression) by averaging the model output of the respective simulations for every time step, i.e. for every hour. To be precise, the simulated runoff time series of five model runs based on calibrated parameter sets of the five nearest neighbours (near in the attribute space) as well as the simulated runoff of two model runs based on parameter sets derived by kriging and regression were combined by computing the mean of the seven time series. As a result of this procedure, the regional- ized simulated runoff of a catchment is not based on a single but on seven different parameter sets. It should be noted that we regionalized the runoff simulations not only for the ungauged catchments, but for all our study catchments, even for those where discharge measurements were available. We did this to guarantee a homogeneous database for our further analysis. This means that the pool of calibrated and regionalized catchments partly overlaps in space (cf. Fig. 1). The regionalization of the catchments with available discharge measurements allows for a validation of the regionalization procedure using the jack-knife technique, a cross-validation approach that showed good model efficiencies for the regionalized runoff, e.g. a median Nash-Sutcliffe efficiency (NSE) of 0.72 for the tested catchments (see Viviroli et al., 2009c for details).

Although the absolute numbers of calibrated (163) and regionalized (186) catchments do not differ substantially, their spatial distribution does (cf. Fig. 1): the calibrated catchments encompass an overall smaller area because of their smaller average size $\left(110 \mathrm{~km}^{2}\right.$ opposed to $250 \mathrm{~km}^{2}$ for the regionalized catchments) and, besides, the calibrated catchments are unevenly distributed, which is why regionalization could significantly extend our catchment database to high and southern alpine areas. Since the high alpine areas are expected to be areas that are most vulnerable to changes in 
climate (Birsan et al., 2005; Viviroli et al., 2011), regionalization was a prerequisite in this study.

\section{Physiographic catchment properties}

The physiographic properties that will be used to characterize the catchments (Table 1) were derived from the HRU-based spatial information gathered during the pre-processing of the data for the hydrological model. The data are gained from a digital elevation model (DEM, $100 \times 100 \mathrm{~m}^{2}$ ), a soil map $(1: 200000)$ and a land use map $\left(100 \times 100 \mathrm{~m}^{2}\right)$, all provided by the Swiss Federal Statistical Office (SFSO, 2003). The digital maps are joined and provided at a spatial resolution of $500 \times 500 \mathrm{~m}^{2}$. For use as characterising properties, the HRUbased data are summed up to the catchment scale.

\subsection{Scenario data}

\subsubsection{Climate scenarios}

We applied climate scenarios of expected changes (deltas) in the annual cycle of temperature and precipitation that are part of the latest release of downscaled climate scenarios for the area of Switzerland (CH2011, 2011). The change signals between the control (1980-2009) and the scenario periods (2021-2050 and 2070-2099) were provided for each day of the year and each observation station in Switzerland (Bosshard et al., 2011). For every station site, a total of ten model chains from the ENSEMBLES-project (van der Linden and Mitchell, 2009) were analysed, each consisting of one of five GCMs driving one of eight RCMs, whereas all model chains assume the SRES A1B emission scenario. Bosshard et al. (2011) applied a spectral smoothing method to filter the annual cycle of change signals, which resulted in considerably better representations of the climate change signals' annual cycle compared to the commonly applied moving averaging window. A bias correction of the climate model output is implicitly incorporated in this downscaling method.

\subsubsection{Scenarios of glacier retreat}

In addition to the climate scenario data itself, we accounted for the accompanying glacier retreat, too. The scenarios assume a mean response time of $50 \mathrm{yr}$. The increase in equilibrium line was calculated according to three different temperature increases (a low, a middle and a high increase) that were classified from the range of all temperature increases of the climate scenarios in use. Further details on the methodology can be found in Paul et al. (2007) and in Linsbauer et al. (2012).

\subsubsection{Hydrological projections}

The observed time series of precipitation and temperature were scaled with the annual cycles of climate change signals. Thereby, we generated a set of climate scenarios with which we ran the catchment models. We simulated the runoff for the control period from 1984 to 2005 and for the two scenario periods from 2025 to 2046 (near future) and 2074 to 2095 (far future) for every catchment and climate scenario. These periods slightly differ from the scenario periods mentioned in Sect. 2.2.1, because they are based on the calibration and validation period of the hydrological model. We calculated the mean annual cycle of monthly runoff and derived the monthly change signals, afterwards, being the ratios of scenario runoff over control period runoff. We aggregated the simulated hourly time series to mean annual cycles of monthly values, because the focus is on changes in the hydrological regime, here, and not on peak flows, for example. Finally, we computed the ensemble mean of the ten hydrological projections per catchment and scenario period.

\section{Methods}

The analysis in this study consists of three steps that are explained in this section: (1) the classification of catchments through cluster analysis based on the catchments' hydroclimatological change signals, (2) the evaluation of the clusters' climate-sensitivity and (3) the mapping of hydrological change to both the climate change signals and the catchment properties by means of redundancy analysis.

For the remainder of this paper, we will refer to three distinct change signals mentioned in the previous paragraph that are specified at this point: (A) the climate change signal comprising annual cycles of monthly temperature and precipitation deltas, (B) the hydrological change signal consisting of the annual cycle of monthly runoff deltas, and (C) the hydroclimatological change signal combining signals A and B. For all change signals, the ensemble means of the ten different projections are computed, thus providing single annual cycles per catchment that result from the spread of the ten scenarios.

We used the R version 2.14.1 (R Development Core Team, 2011) for our analyses in general and in particular the $R$ package vegan, version 2.0-2 (Oksanen et al., 2011) for the redundancy analysis.

\subsection{Cluster analysis}

We classified the study catchments with respect to their hydro-climatological change signals, because the same climate signal might cause different hydrological signals in different catchments: considering all signals together facilitates distinguishing clearer clusters. The hydro-climatological change signals were clustered threefold: for the near and the far future period alone and for both periods in combination.

We applied a hierarchical agglomerative clustering based on Ward's minimum variance method. This algorithm starts with $n$ clusters, i.e. as many clusters as catchments considered, and successively merges the individuals based on their 
Table 1. Physiographic catchment properties.

\begin{tabular}{|c|c|c|c|}
\hline Abbreviation & Description & Unit & Scale type \\
\hline catch_area & Catchment area & $\mathrm{km}^{2}$ & Ratio \\
\hline mean_alt & Mean altitude & ma.s.l. & Ratio \\
\hline elv_range & Elevation range (altitude $_{\max }-$ altitude $_{\min }$ ) & $\mathrm{m}$ & Ratio \\
\hline mean_slo & Mean slope of the catchment & $\circ$ & Ratio \\
\hline mean_afc & Mean available field capacity & Vol \% & Ratio \\
\hline mean_sdp & Mean soil depth & $\mathrm{m}$ & Ratio \\
\hline gl_ctrl_rel & Relative glaciated area (control period) & $\%$ & Ratio \\
\hline gl_near_rel & Relative glaciated area (near future, 2025-2046) & $\%$ & Ratio \\
\hline gl_far_rel & Relative glaciated area (far future, 2074-2095) & $\%$ & Ratio \\
\hline domnt_asp & $\begin{array}{l}\text { Dominant aspect class (the mode of the aspect classes, } \\
1=\text { North, } 2=\text { East, } 3=\text { South, } 4=\text { West) }\end{array}$ & - & Nominal \\
\hline domnt_lu & $\begin{array}{l}\text { Dominant land use (the mode of the land use types, } \\
1=\text { coniferous forest, } 2=\text { deciduous forest, } 3=\text { mixed forest, } \\
4=\text { pasture, } 5=\text { bare ice, } 6=\text { rock, } 7=\text { sub-alpine meadow, } 8=\text { coniferous forest } / \text { rock) }\end{array}$ & - & Nominal \\
\hline
\end{tabular}

similarity that is measured by Euclidean distances. More precisely, the sum of the squared distances among the members of a cluster, divided by the number of the members, is to be minimized (see e.g. Borcard et al., 2011). The result of this kind of clustering method is always a dendrogram, a tree-like graph where every fusion of two branches (i.e. the merging of two clusters) indicates a level of generalization. The length of a branch can be interpreted as the dissimilarity between clusters and can be used to assist in deciding on the number of clusters $k$. The decision on $k$, however, remains a subjective choice to a certain extent, and there is not one objectively right solution (Leyer and Wesche, 2007). It has to be stated that there are various clustering methods (see e.g. Borcard et al., 2011 for an overview) and none of them can be objectively rated as the best method (Hannah et al., 2005). A number of studies that tested different clustering methods for their use in catchment classification found that Ward's minimum variance method yields robust and physically meaningful results (e.g. Bower et al., 2004; Gobena and Gan, 2006; Kingston et al., 2011). Therefore, we chose this method for our study.

\subsection{Physiographic catchment properties}

The resulting clusters were characterized by the catchment properties mentioned above. We reduced the set of quantitative variables ("ratio scale" in Table 1) by means of correlation analysis (Fig. 2) to exclude those variables that share the same or similar information. A Pearson's correlation coefficient $(r)$ or Kendall's tau $(\tau)$ higher than 0.7 indicates high correlations (Leyer and Wesche, 2007), and one of the correlated variables is dismissed from further analysis.

Mean slope, mean field capacity and mean soil depth are highly correlated among each other. Because field capacity and soil depth are variables derived from the soil map that has a relatively low spatial resolution (see subsection "Phys- iographic catchment properties" of Sect. 2.1), they are assumed to be less precise and are excluded from the set of catchment properties. Mean slope is also highly correlated with mean altitude, but they are both used in further analysis because they are expected to impact different hydrological processes, i.e. the slope is supposed to rule runoff generating processes, whereas the mean altitude (as an indicator of temperature) governs, for example, snow and glacier melt processes. From the two correlated variables mean altitude and elevation range, we apply mean altitude in our further analysis because of its superior significance for hydrological processes (Weingartner, 1999). The variables dominant aspect and dominant land use are used in further analysis, but they are not tested for correlations because they are of nominal scale.

\subsection{Redundancy analysis}

Redundancy analysis (RDA) is the canonical or constrained version of a principal components analysis (PCA) and combines multiple linear regression with classical ordination; for a detailed explanation, see Borcard et al. (2011) and Legendre and Legendre (1998). Briefly, while classical ordination is a method of dimension reduction designed to extract the dominant structures in a single data set, constrained ordination extracts that part of the variation of a data set that is a function of the variation in another data set (Borcard et al., 2011). In other words, constrained ordination only describes the variation of the data that can be explained by the constraints (Oksanen et al., 2011). The canonical axes that are derived represent linear combinations of the explanatory, i.e. the constraining variables that best explain the variation in the matrix of the response variables (Borcard et al., 2011; Legendre et al., 2011).

We used this canonical ordination method primarily as a graphical tool in our study, like Oksanen et al. (2011) 


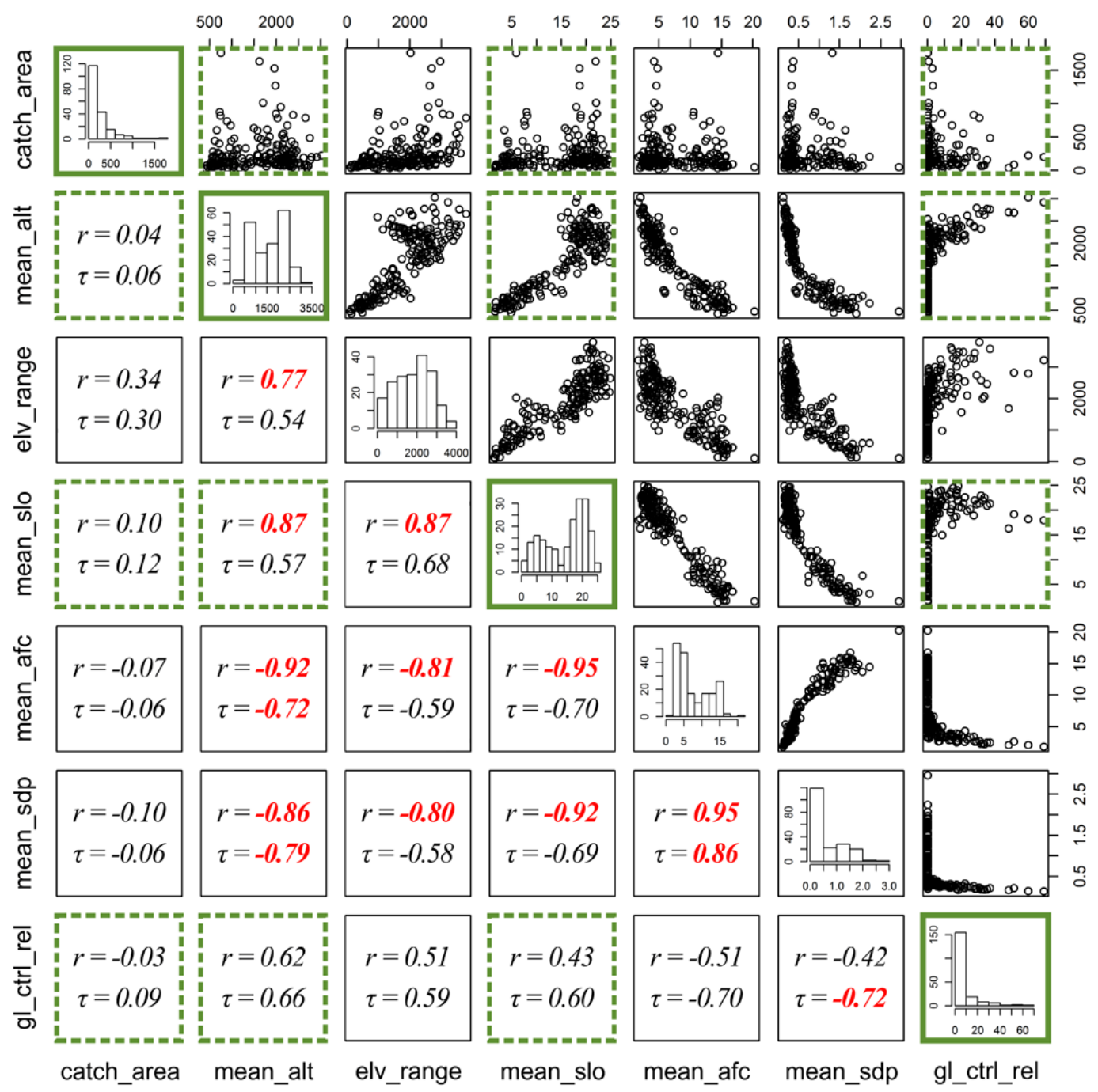

Fig. 2. Correlation analysis of physiographic catchment properties (for abbreviations see Table 1). For each pair of variables, a scatter plot (upper right part of the figure) and Pearson's correlation coefficient $(r)$ as well as Kendall's tau ( $\tau$ ) are given (lower left part of the figure). Red values indicate high correlations ( $>0.7)$. In between, the histogram of each variable is displayed to visualize its distribution. The variables whose histograms are marked with a green box are used in further analyses.

suggested, although the quantitative information associated with the RDA-axes was employed to evaluate the reliability of the derived relationships. Each RDA-axis explains a certain amount of the total variance of the response variables, which is equivalent to an $R^{2}$ in multiple regression. This $R^{2}$ is biased, though, and one should, therefore, compute an adjusted $R_{\text {adj }}^{2}$ (for details, see Borcard et al., 2011).

In a first step, all catchments were assessed together to gain insight into the overall governing structures in the data set. In doing so, redundancy analysis was used to verify the results of the cluster analysis: if the catchments of a cluster are grouped together in the RDA, too, one can assume a robust clustering of the catchments. Then, the clusters were separately analysed to assess the cluster-specific dominant explanatory variables. The response variables were the hy- drological change signals, whereas the matrix of explanatory variables consists of the climate change signals and the physiographic catchment properties. To reduce the number of explanatory variables, the monthly climate change signals were aggregated to seasonal signals by computing the seasonal mean. This was necessary because, for $m$ (number of explanatory variables) approaching $n$ (number of objects, i.e. catchments), the constraints become meaningless and the RDA is more similar to a PCA (Oksanen et al., 2011). 

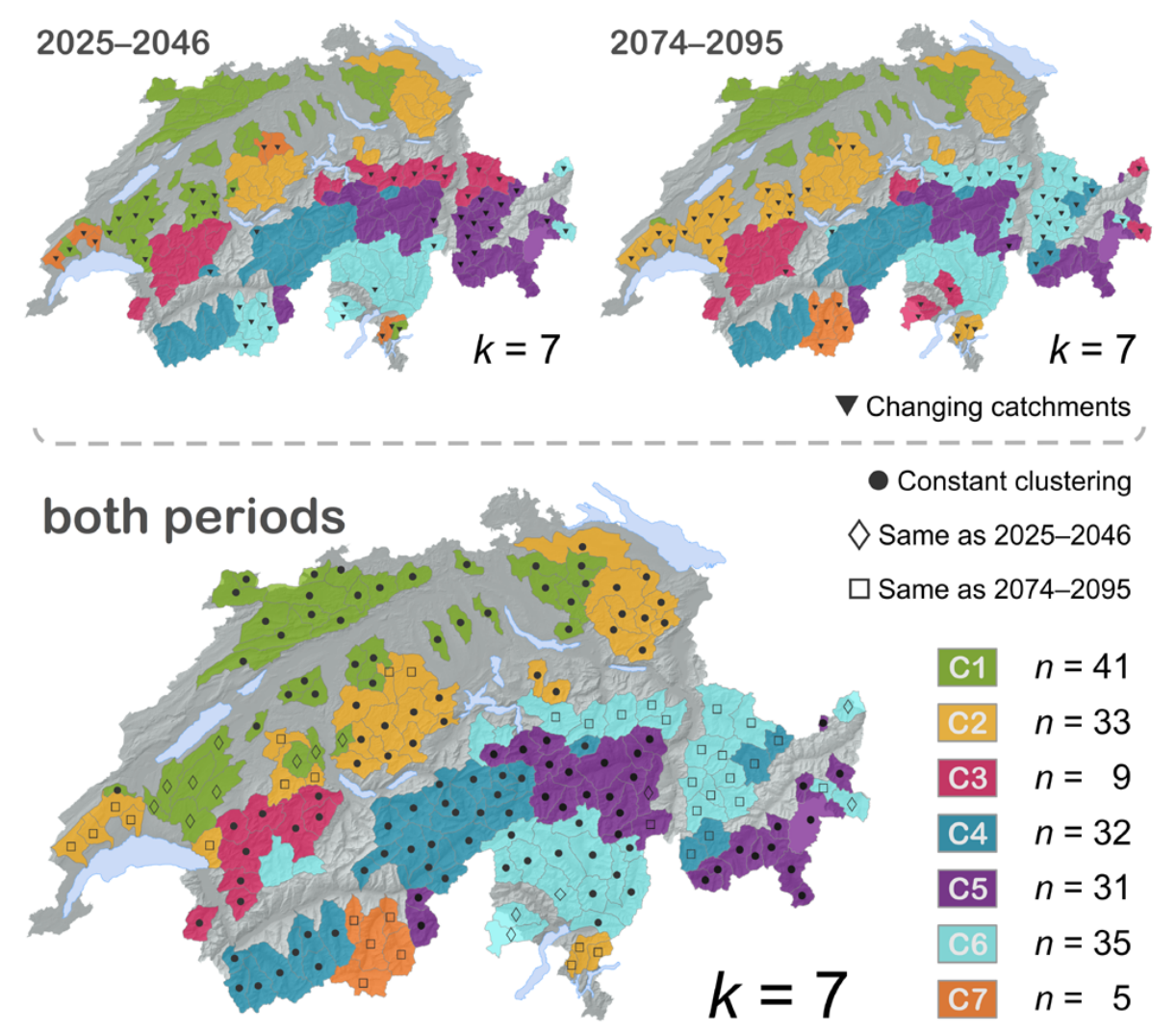

Fig. 3. Cluster analysis for hydro-climatological change signals of the near future (2025-2046, upper left panel), the far future (2074-2095, upper right panel) and both periods in combination (lower panel). The number of cluster members $n$ is given for every cluster. The catchments that are assigned to the same cluster in all three versions are marked with a solid circle in the lower panel.

\section{Results}

\subsection{Cluster analysis and sensitive catchments}

The catchments' hydro-climatological change signals were clustered for the near and the far future period alone and for both periods together (Fig. 3). The number of clusters $k$ was determined with the aid of the resulting dendrograms as well as our knowledge about the study region: the climatically distinct southern alpine region with its typical two-peaked hydrological regime, for example, should be separated from the adjacent high alpine area in all three clustering modes, which was the case for $k=7$. We refer to the seven clusters as $\mathrm{C} 1$ to $\mathrm{C} 7$.

The clusters of all three versions are spatially coherent, and the distribution of the clusters mirrors the landscape types depicted in Fig. 1 to a certain degree. Comparing the clusters of the near and the far future, altogether 55 catchments are assigned to different clusters between those periods (referred to as changing catchments). Particularly remarkable are the catchments that switch to $\mathrm{C} 6$ in the far future, because this cluster was the southern alpine cluster mentioned above that we wanted to separate from the others.
Analysis of the switching catchments' hydrological regime, however, revealed that their regime switched to the twopeaked southern regimes, too (FOEN, 2012), which explains their grouping in the far future period. Another interesting feature is the combined clustering preserves either the clusters of the near or the far future and does not generate completely new clusters. In most cases, the clustering of the far future is preserved in the combined clustering, though, this might be ascribed to the clearer hydro-climatological signal in that period. For our further analyses, we will use the clustering based on both periods in combination (Fig. 3, lower panel).

The physiographic properties of the clustered catchments are summarized in a parallel coordinates plot (Fig. 4). Each parallel axis displays the range of values of a physiographic variable, and each curve represents a single catchment with its characteristic properties. The curves are colour-coded according to the cluster a catchment belongs to. The graph can be read from left to right examining, for example, the mean values of a single cluster (coloured circles) or it can be studied axis-wise comparing the clusters with respect to a specific variable. The variable catchment area does not differ much amongst the clusters. In other words, the clusters' 


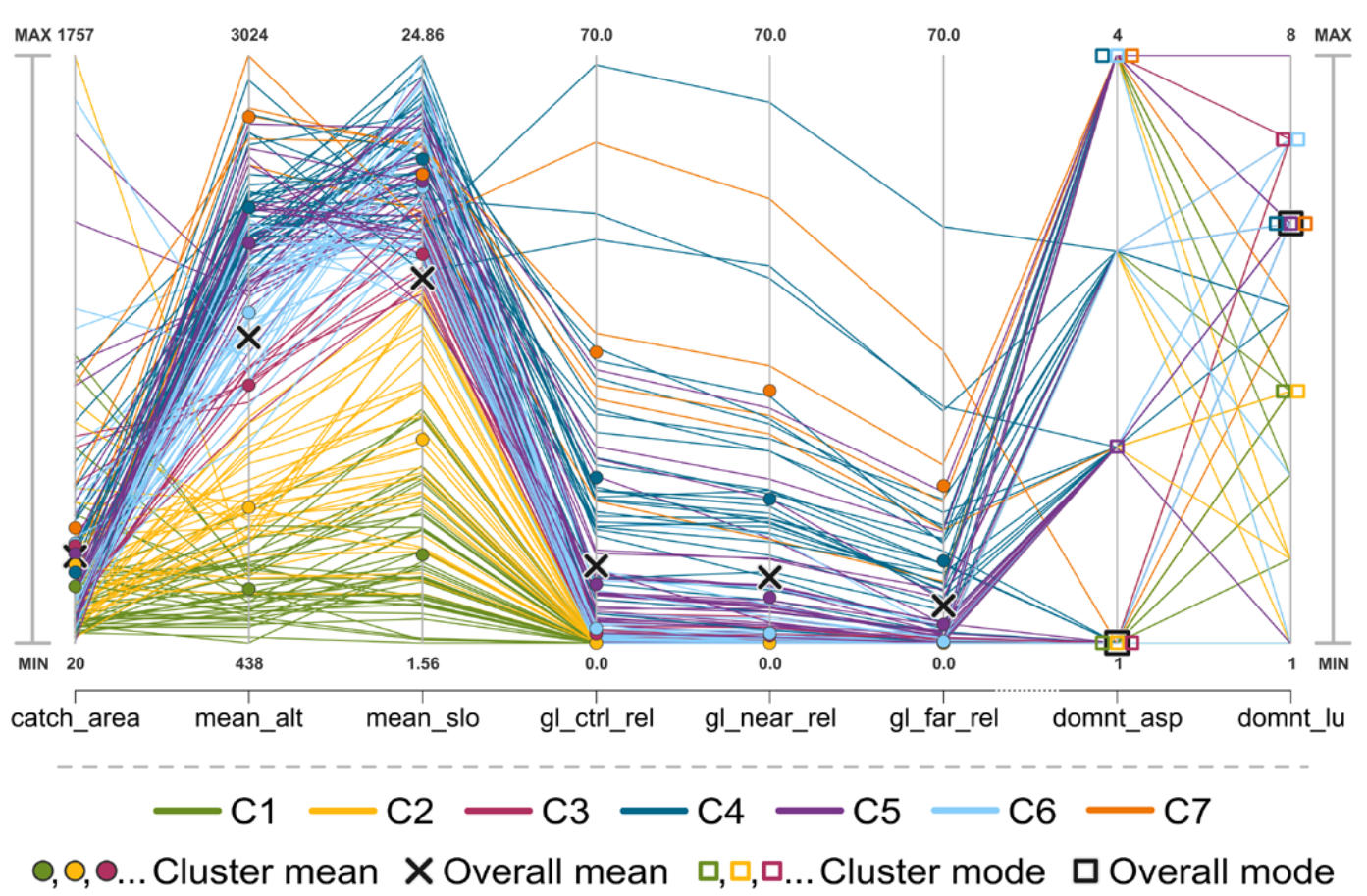

Fig. 4. Parallel coordinates plot of the physiographic catchment properties (for abbreviations and class descriptions of the nominal variables dominant aspect and dominant land use, see Table 1). Each parallel axis displays one physiographic variable, and each curve represents a catchment. The curves are colour-coded according to the cluster a catchment is assigned to.

mean values vary around the overall mean. Unlike the catchment area, mean altitude and mean slope are two variables that clearly distinguish the clusters. The high correlation of those two variables (Fig. 2) is visible in the parallel coordinates plot, too. The clusters with glaciated catchments can be subdivided into two clusters (C4 and $\mathrm{C} 7$ ) that are still considerably glaciated in the far future, one intermediate cluster (C5) and two clusters ( $\mathrm{C} 3$ and $\mathrm{C} 6$ ) that are projected to be nearly ice-free by the end of the century. The clusters' modes for the nominally scaled variable dominant aspect also depict a clear pattern. Clusters $\mathrm{C} 1$ to $\mathrm{C} 3$, which are situated north of the alpine ridge, are mostly north-exposed. Catchments in C5, which generally drain eastwards, are east-exposed (aspect class 2), accordingly. The other clusters are mainly westexposed. For dominant land use, a correlation of the clusters' modes with their mean elevation can be observed. In $\mathrm{C} 1$ and $\mathrm{C} 2$, having a mean elevation of $1000 \mathrm{~m}$ a.s.l. and less, the dominant land use is pasture. $\mathrm{C} 3$ and $\mathrm{C} 6$ are mainly covered with subalpine meadow and are situated between 1500 and $2000 \mathrm{~m}$ a.s.l. For clusters situated above $2000 \mathrm{~m}$ a.s.l. on average ( $\mathrm{C} 4, \mathrm{C} 5$ and $\mathrm{C} 7)$, the dominant land use is rock.

The hydro-climatological change signals of the clusters (Fig. 5, rows 1 to 4 from top) show clear annual cycles with maxima in summer for temperature and minima in summer for precipitation and runoff. The rather slight changes that can be observed for the near future period are visibly amplified in the far future for all change signals. The amount of decreasing summer precipitation is considerably smaller than that of the summer runoff, which means that the temperature change signal determines the change in runoff to a large extent. Unlike the climate change signals that hardly differentiate among the clusters, the hydrological change exhibits an obvious spread. This confirms our assumption that the same climate change signal, indeed, can induce very different hydrological responses.

Concerning climate sensitivity in the near future period, the clusters can be regarded as non-sensitive. Although slight changes in near future runoff can be observed for all clusters except C1 (Jura Mountains, Swiss Plateau), these changes are negligible with respect to the absolute monthly runoff (see lower left panel in Fig. 5). In the far future period, C1 stays insensitive to the clear changes in climate. Although the relative change in the summer of the far future is comparable to that of the other clusters (fourth row from top in Fig. 5), this change is still a small absolute deviance $(-25 \%$ but only $-10 \mathrm{~mm} \mathrm{month}^{-1}$ ). On the contrary, $\mathrm{C} 2$, which experiences about the same climate change in the far future period as $\mathrm{C} 1$, exhibits discernible absolute and relative changes in runoff. The physiographic properties that differ between those clusters are mean altitude and mean slope, which indicates an influence of those variables on the projected hydrological change. The yearly peak runoff of C5 and C6 is shifted one month earlier and is projected to significantly decrease in the far future (lower right panel in Fig. 5). The shift 

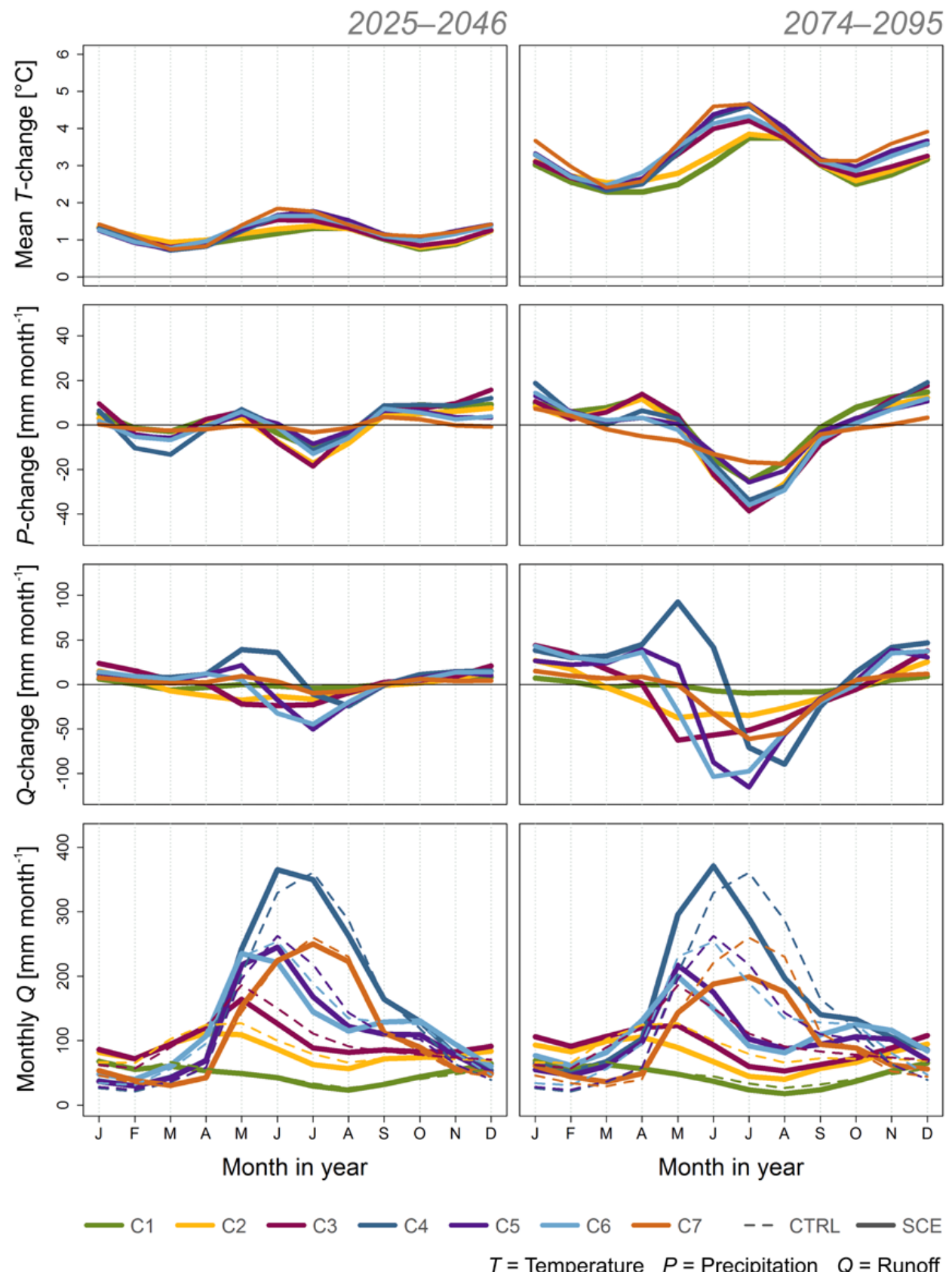

$$
T=\text { Temperature } P=\text { Precipitation } Q=\text { Runoff }
$$

Fig. 5. Hydro-climatological change signals per cluster (absolute temperature, precipitation and runoff change, rows 1 to 3 from top), relative runoff change (4th row) and absolute monthly runoff (bottom row) for the control period (CTRL, dashed lines), the near future period (SCE, solid lines in left column) and the far future period (SCE, solid lines in right column). The change signals are given as absolute values to facilitate direct comparison with the absolute monthly runoff.

in peak runoff applies to $\mathrm{C} 4$, too, with the exception that the peak is projected to increase, here. The most obvious difference between $\mathrm{C} 4$ and $\mathrm{C} 5 / \mathrm{C} 6$ is their glaciation, which is on average still $10 \%$ for $\mathrm{C} 4$ in the far future, whereas the mean values of $\mathrm{C} 5$ and $\mathrm{C} 6$ are $3 \%$ and nearly zero, respectively. Moreover, $\mathrm{C} 4$ has a higher mean altitude than $\mathrm{C} 5$ and $\mathrm{C} 6$, meaning that increasing winter precipitation is to a cer- tain extent solid precipitation causing increasing snowmelt in spring. This, together with a still existing glacier melt, explains the increasing yearly peak runoff. This is not true, however, for $\mathrm{C}$, the cluster with the highest mean altitude and glaciation, where the projected peak runoff decreases in the far future. This decrease is the result of the smaller glaciated area compared to the control period (that applies 
to the other glaciated cluster, too, of course) as well as the decreasing summer precipitation. C7 does not show the increase in spring runoff that $\mathrm{C} 4$ exhibits because of the high mean altitude of this cluster and therewith the low mean temperature: the temperature is low enough to preserve the control period's ice-fed regime in the far future period. Moreover, temperature is the reason why winter runoff does not increase significantly in $\mathrm{C} 7$, too, because the ratio of liquid to solid precipitation does not change markedly. That is, the mean altitude of a catchment and therewith the temperature are features that strongly determine hydrological change.

\subsection{Redundancy analysis}

The redundancy analysis confirms the results of the cluster analysis because the same catchments are grouped together in the RDA-biplot, too (Fig. 6, upper panel). It should be noted that the catchments are only colour-coded according to the corresponding cluster, but the cluster itself was not a constraint in the RDA. Besides this obvious result, biplots are interpreted according to certain rules (cf. e.g. Borcard et al., 2011; Leyer and Wesche, 2007; Oksanen et al., 2011 and see the RDA schematic in Fig. 6):

1. Only the first two (and most important) canonical axes are displayed; their proportion of explained variance of the dependent variables is given as $R_{\text {adj }}^{2}$.

2. A constraining variable's vector points to the direction of the variable's gradient, and the arrow's length, projected on each of the two canonical axes at a right angle, indicates the strength of this variable. The absolute length of a vector has no meaning, but it can be assessed relative to the length of the other vectors.

3. The response variables (i.e. the catchments, Fig. 6, upper panel, or the monthly runoff change signals, Fig. 6 , lower panel) are projected at a right angle on a constraining variable's vector. They are ordered along the vector according to the relative importance the constraint has for the response variable.

4. Distances between the response variables and the centroids of nominally scaled constraining variables (here: aspect and land use) approximate their Euclidean distances in the multidimensional space; the nearer a response variable to the constraint's centroid, the more of the variance is explained by the constraint.

The analysis of the entire set of catchments (Fig. 6) provides insight into the general structure of explanatory and dependent variables. The overall $R_{\text {adj }}^{2}$ is 0.79 , meaning that the variance of explanatory variables explains roughly $80 \%$ of the variance of the dependent variables. This is a fairly high value that indicates we have assessed the important constraints in our analysis. The first RDA axis accounts for the major part, i.e. $63 \%$ of the variance, and this axis is strongly determined by mean altitude, mean slope and summer and autumn temperature change of both periods. The second RDA axis, in contrast, explains only $8 \%$ of the variance of the response variables.

The set of catchments is divided into northward $(\mathrm{C} 1, \mathrm{C} 2$, C3 and C7, Fig. 6, upper panel) and south- and eastward exposed catchments (C4, C5, C6). Furthermore, the colourcoded clusters are distributed along the first RDA axis from right to left, roughly sorted depending on their mean altitude. At the same time, they are spread in relation to land use type that itself is a function of elevation. For highly elevated catchments (C4, C5, C6), the importance of the temperature change is proportionately higher, too. The highest catchments, however, exhibit strikingly different behaviours (C7 in Fig. 6, upper panel); these catchments' hydrological change signals depend on the precipitation delta and on glaciation, which matches our findings from the cluster analysis. The dispersion of catchments along the second RDA axis is mainly a function of glaciation for the high elevated catchments (C4 and partly C5 and C7) as well as a function of spring temperature change for the catchments at lower elevations ( $22, \mathrm{C} 3, \mathrm{C} 6$ and partly $\mathrm{C} 5)$, indicating an influence of snowmelt processes on the hydrological response for the latter ones.

Regarding the hydrological change signals (Fig. 6, lower panel), the variance of the near future's change signals is generally smaller compared to those of the far future because they are distributed around the origin of the RDA axes. This reflects the lower climate sensitivity during the near future period that we found in cluster analysis. The land use type does not constrain the monthly hydrological change; it seems to be only characterising for the entire annual cycle of change signals (represented by the centroid of a catchment). There is a strong dependence of spring and summer runoff change on the glaciation of a catchment. The change in winter and spring runoff is also a function of the catchments' mean altitude and is thereby a function of winter and spring temperature change, determining the ratio of liquid to solid precipitation as well as snowmelt processes. Whereas the summer precipitation delta has an influence on changes in summer runoff, the other seasonal precipitation deltas do not determine hydrological change.

For the analysis of single clusters, the set of constraining variables had to be further reduced because the $n$ of single clusters is smaller (cf. Sect. 3.3). First of all, we assessed only the sensitive far future period and excluded dominant land use and catchment area from the set of constraints, because they showed to be less important for the monthly runoff change (cf. Fig. 6, lower panel). C3 and C7 were not analysed at all because their number of cluster members was too small as opposed to the number of constraining variables. In fact, there would have been more constraints than objects to explain. The results of the redundancy analysis for single clusters (Fig. 7) are summarized in Table 2. 


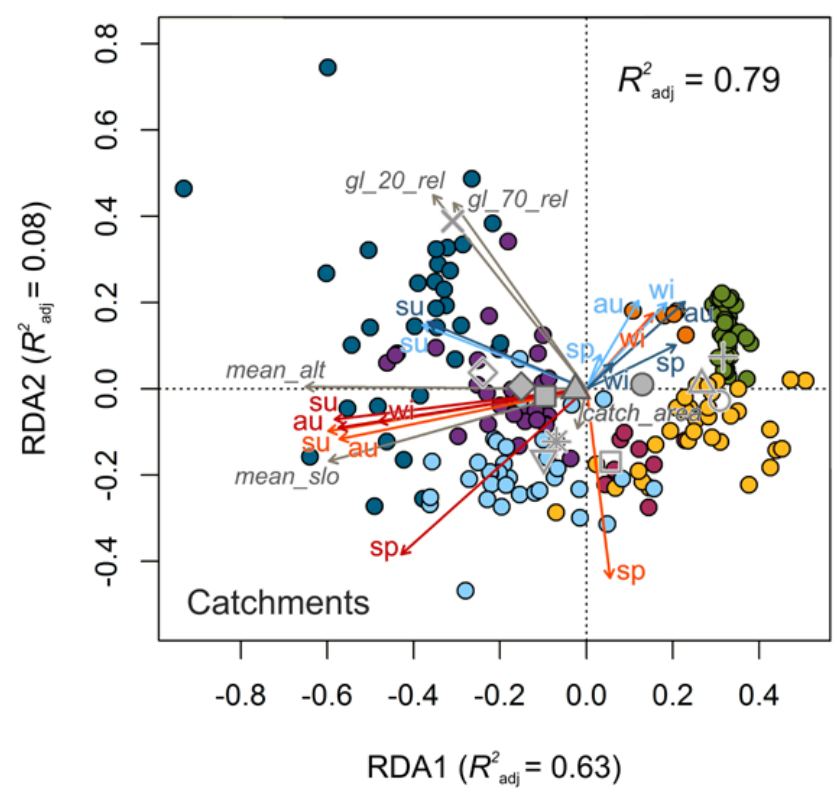

\section{LEGEND}

RDA schematic

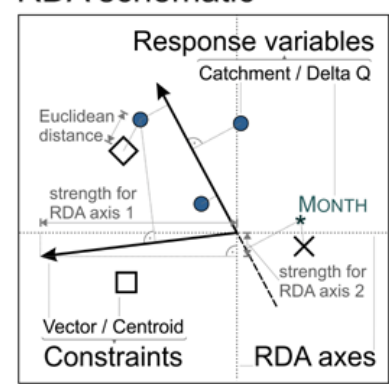

\section{Response variables}

\section{Centroids catchments} (Colors indicate corresponding cluster) - $\bigcirc \bigcirc 0 \%$ $\begin{array}{lllllll}\mathrm{C} 1 & \mathrm{C} 2 & \mathrm{C} 3 & \mathrm{C} 4 & \mathrm{C} 5 & \mathrm{C} 6 & \mathrm{C} 7\end{array}$ *,* Centroids Delta $Q$ (near, far)

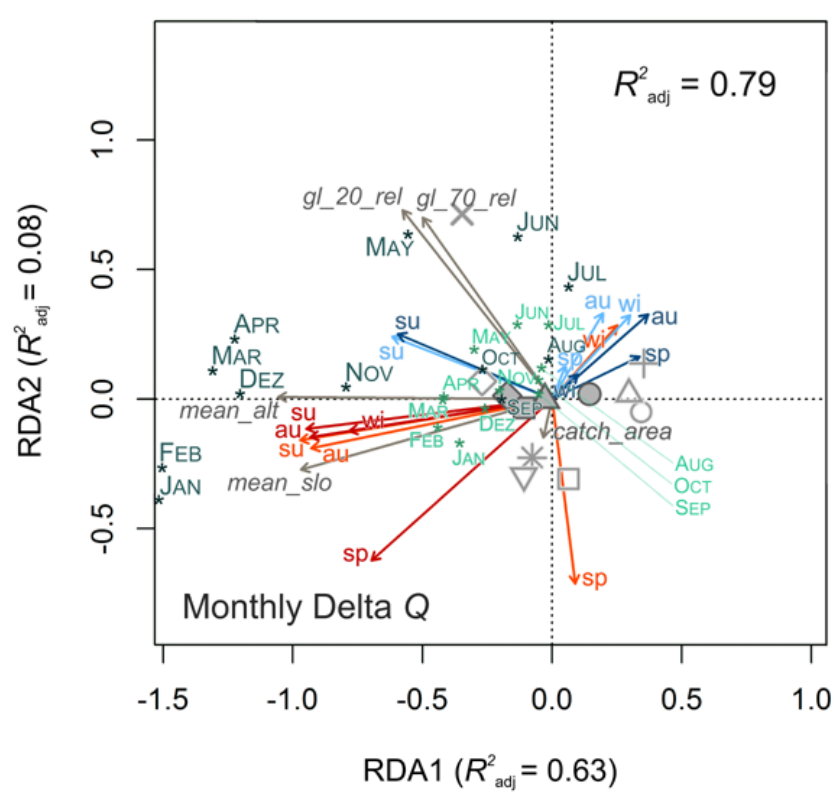

\section{Constraining variables}

Vectors

$\uparrow$ Catchment properties

, $\mathcal{\nearrow}$ Delta $T$ (near, far)

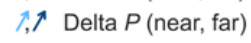

\section{Centroids land use}

$\square$ Coniferous forest

Deciduous forest

$\triangle$ Mixed forest

+ Pasture

$\times$ Bare ice

$\checkmark$ Rock

$\nabla$ Sub-Alpine meadow

* Coniferous f./Rock

Centroids aspect

O North $\left(315^{\circ}-45^{\circ}\right)$

ㅁ. East $\left(45^{\circ}-135^{\circ}\right)$

$\diamond$ South $\left(135^{\circ}-225^{\circ}\right)$

$\triangle$ West $\left(225^{\circ}-315^{\circ}\right)$

Fig. 6. RDA-biplots for all catchments and both scenario periods. At the top of the legend, a schematic of an RDA with its different components is given (cf. Sect. 4.2 for interpretation rules). The upper panel shows a biplot of the catchments; the lower panel displays the same results but with respect to monthly runoff changes (Delta $Q$ ). The vectors of the seasonal Delta $T$ and $P$ are indicated with abbreviations "wi", "sp", "su" and "au". Both change signals are displayed for the near (orange and light blue) and the far (red and dark blue) future. The adjusted $R^{2}\left(R_{\text {adj }}^{2}\right)$ is the proportion of variance of the response variables explained by the constraining variables.

$\mathrm{C} 1$ and $\mathrm{C} 2$ are the only clusters where a clear impact of mean slope on the monthly runoff change was observed. At the same time, precipitation change influences the change in runoff during the whole year in those two clusters. This suggests that hydrological processes that are related to the slope of a catchment are dependent on the precipitation delta. In $\mathrm{C} 2$, the winter temperature delta is important for runoff change, too, indicating an additional impact of an altered ra- tio of liquid to solid precipitation, here. The small ( $>10 \%$, $\mathrm{C} 1)$ to medium $(>30 \%, \mathrm{C} 2)$ seasonal changes in runoff in the far future period are averaged out over the whole year. This is different for $\mathrm{C} 4$ to $\mathrm{C} 6$, where a small $(>+10 \%)$ to large $(>+50 \%)$ increase in the far future's yearly runoff was projected despite of decreasing summer runoff. This yearly increase is highest for the highly glaciated $\mathrm{C} 4$. Mean altitude is important in all clusters tested separately, but its impact is 

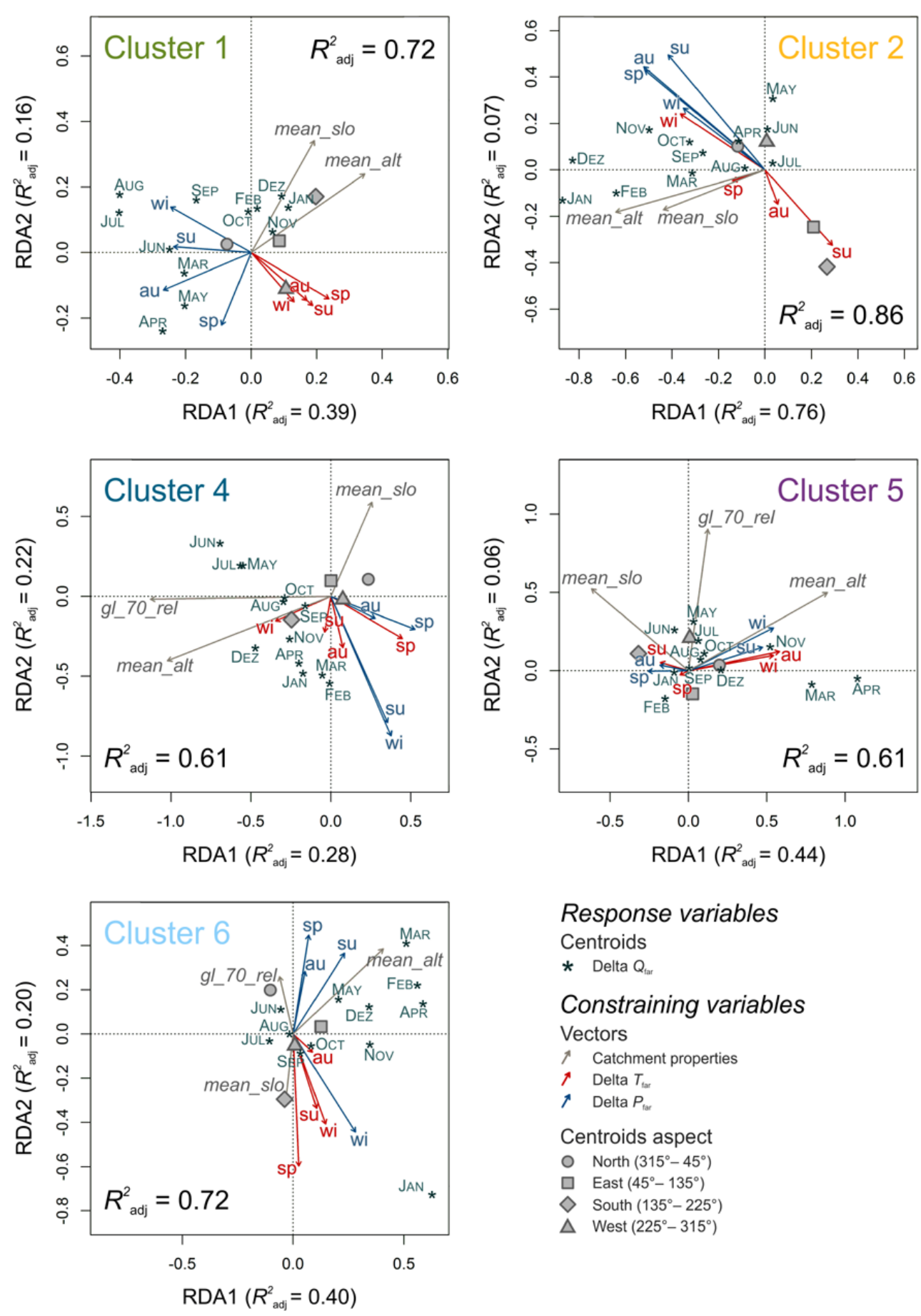

Response variables

Centroids

* Delta $Q_{\text {tio }}$

Constraining variables

Vectors

$\nexists$ Catchment properties

1 Delta $T_{\text {tos }}$

1 Delta $P_{\text {tor }}$

Centroids aspect

○ North $\left(315^{\circ}-45^{\circ}\right)$

ㄷast $\left(45^{\circ}-135^{\circ}\right)$

$\diamond$ South $\left(135^{\circ}-225^{\circ}\right)$

$\triangle$ West $\left(225^{\circ}-315^{\circ}\right)$

Fig. 7. RDA results for the far future period and single clusters. Clusters three and seven were not analysed because of their too small numbers of cluster members. For explanation of the vector names, see Fig. 6. Note that Clusters 1 and 2 are not glaciated and therefore miss glaciation as a constraining variable.

less pronounced in $\mathrm{C} 4$, where the glaciation is most important. In summary, the RDA for single clusters underlines our previous findings where mean altitude and thereby the temperature of a catchment are the dominant factors determining hydrological change.

\section{Discussion and conclusions}

We introduced an approach to reduce a comprehensive set of 186 catchments in Switzerland to fewer response types to climate change. We then inferred general relationships 
Table 2. Summary of summer (JJA), winter (DJF) and yearly (a) runoff changes $(Q)$ per cluster and scenario period (near, far) and evaluation of the constraints from redundancy analysis. Explanation of symbols: increase/decrease $<10 \%(\approx), 10-29 \%(+/-)$, 30-50\% (++/--), $>50 \%(+++/---)$. Yearly peak increased $(\uparrow)$, decreased $(\downarrow)$ or shifted earlier $(\leftarrow)$. Influence of constraint $(\mathrm{x})$, strong influence of constraint $(\mathrm{xx})$. For influence of the climate change signal $(\Delta T, \Delta P)$, the respective seasons are indicated. $R_{\text {adj }}^{2}=$ proportion of variance explained by constraints.

\begin{tabular}{|c|c|c|c|c|c|c|c|}
\hline & $\mathrm{C} 1$ & $\mathrm{C} 2$ & $\mathrm{C} 3^{*}$ & $\mathrm{C} 4$ & C5 & C6 & $\mathrm{C}^{*}$ \\
\hline$Q_{\mathrm{JJA}, \text { near }}$ & $\approx$ & - & - & $\approx$ & - & - & $\approx$ \\
\hline$Q_{\mathrm{DJF}, \text { near }}$ & $\approx$ & + & ++ & ++ & + & ++ & + \\
\hline$Q_{\mathrm{a}, \text { near }}$ & $\approx$ & $\approx$ & $\approx$ & + & $\approx$ & $\approx$ & $\approx$ \\
\hline Peak $_{\mathrm{a}, \text { near }}$ & $\approx$ & $\downarrow \leftarrow$ & $\downarrow$ & $\uparrow \leftarrow$ & $\downarrow$ & $\downarrow \leftarrow$ & $\downarrow$ \\
\hline$Q_{\mathrm{JJA}, \text { far }}$ & - & -- & -- & - & -- & -- & - \\
\hline$Q_{\mathrm{DJF}, \mathrm{far}}$ & + & ++ & +++ & +++ & +++ & +++ & + \\
\hline$Q_{\mathrm{a}, \mathrm{far}}$ & $\approx$ & $\approx$ & $\approx$ & +++ & ++ & + & $\approx$ \\
\hline Peak $_{\mathrm{a}, \text { far }}$ & $\approx$ & $\downarrow \leftarrow$ & $\downarrow$ & $\uparrow \leftarrow$ & $\downarrow \leftarrow$ & $\downarrow \leftarrow$ & $\downarrow$ \\
\hline$\Delta T_{\text {far }}$ & & djf & $*$ & mam & djf, son & & * \\
\hline$\Delta P_{\text {far }}$ & all & all & $*$ & djf, mam, jja & djf, jja & mam, jja, son & $*$ \\
\hline mean_alt & $\mathrm{xx}$ & $\mathrm{xx}$ & $*$ & $\mathrm{x}$ & $\mathrm{xx}$ & $\mathrm{xx}$ & $*$ \\
\hline mean_slo & $\mathrm{xx}$ & $\mathrm{x}$ & $*$ & & & & $*$ \\
\hline gl_rel & & & $*$ & $\mathrm{XX}$ & $\mathrm{x}$ & & * \\
\hline domnt_asp & $\mathrm{x}$ & $\mathrm{x}$ & $*$ & $\mathrm{x}$ & $\mathrm{x}$ & $\mathrm{x}$ & $*$ \\
\hline$R_{\mathrm{adj}}^{2}$ & 0.72 & 0.86 & $*$ & 0.61 & 0.61 & 0.72 & $*$ \\
\hline
\end{tabular}

* C3 and C7 were not separately analysed in redundancy analysis because of the too small numbers of cluster members.

between catchment characteristics, climate change signals and the hydrological responses of the catchments in order to extract the dominant processes that govern hydrological change. The motivation for this study is the adaptation policy that demands hydrological projections, which should support the decision-making on necessary adaptation measures. Hydrological climate-impact studies that provide these projections are highly demanding with respect to computational power and time, however. To simplify future impact studies in Switzerland, we deduced characteristic catchment properties that constitute the hydrological change to a large extent and identified climate-sensitive regions, so that future impact studies can be conducted on a reduced sample of catchments that represent the determining properties and sensitive regions.

In the following, we want to discuss our results with respect to the research questions outlined in the introduction, then evaluate the results' significance for adaption measures and review some sources of uncertainty we did not cover in our analysis. Finally, we propose possible directions where future research could focus on.

\subsection{Research questions}

In our first research question, we sought a grouping of hydrological response. By means of cluster analysis, we grouped the catchments into seven distinct response types. This means that future impact studies for the entire area of Switzerland can be conducted on a subset of catchments representing the different response types.
Regarding the second question that aimed at the response types' climate-sensitivity, we found that all clusters except for one exhibit a clear shift of the annual runoff distribution in the far future period: Summer runoff decreases significantly, whereas winter runoff increases. This shift acts on specific regimes, though, which alters the effect with respect to the absolute monthly runoff. Significant yearly increases in runoff were observed for the high alpine region in addition to the clear seasonal shift. Cluster 1 (C1), which encompasses catchments in the Jura ranges and in parts of the Swiss Plateau, is not sensitive to climate change, neither during the near (2025-2046) nor the far future period (2074-2095). To summarize, all clusters except for $\mathrm{C} 1$ have to be regarded as climate-sensitive in the far future period and their response to climate change is cluster-specific. To reduce the workload of future impact studies, one could focus on catchments in the sensitive regions and assess only the far future period, provided that the near future is not of particular interest.

The third research question aimed at deriving general causal relationships between the hydrological response to climate change and characteristic catchment properties. We conclude that the main determining feature is the catchments' mean elevation, which e.g. Birsan et al. (2005) and Renner and Bernhofer (2011) found, too. Within a certain range of the catchments' mean altitudes, between 1000 and $2500 \mathrm{~m}$ a.s.l., the hydrological change can be regarded as a function of elevation and, therefore, as a function of temperature change. Because elevation governs the mean annual temperature of a catchment, it governs the associated dominant hydro-climatological processes, too, which 
are above all the partitioning of liquid and solid precipitation and the determination of snow accumulation and snow melt. Nijssen et al. (2001) discovered a similar causal relationship between the hydrological response and the latitude of a catchment: more northern catchments, i.e. colder and more snow-dominated catchments, exhibit "[...] the largest changes in the hydrological cycle [...]". For catchments in our study with a mean altitude below $1000 \mathrm{~m}$ a.s.l., hydrological change is mainly a function of precipitation change, which is not nearly as pronounced as the temperature signal is and which is why they are less climate-sensitive. Catchments with a mean altitude above the threshold of approximately $2500 \mathrm{~m}$ a.s.l. exhibit a different behaviour: at these elevations, even strong increases in temperature do not shift the mean annual temperature of a catchment strongly enough, so that snow accumulation and ablation processes would be substantially altered and a change in regime would succeed. This effect was observed by Nijssen et al. (2001), too, but for the most northern (i.e. the coldest) catchments in their study, where " $[\ldots]$ even for a relatively large increase in temperature, winters will remain quite cold with temperatures generally well below freezing". This means that the sample of catchments considered in future impact studies should include catchments at different altitudes and, therefore, with different mean temperatures, even if they are situated in the same response region because of the superior importance of this integral catchment characteristic.

\subsection{Significance for adaptation measures}

In the following, we discuss the general suggestions for future impact studies outlined in the previous section with respect to water resources management and adaptation strategies. Adaptation is a process that has to be dealt with locally and with a distinct focus. We focused on changes in the mean annual cycle, here, and assessed the high alpine regions ( $\mathrm{C} 4$, C5 and partly C6) to be specifically sensitive to changes in climate, which implies a potential need for adaptation. This sensitive hydrological response, however, can actually be advantageous if the focus is on hydropower production, which is the main economic factor in these regions. Hänggi and Weingartner (2012) concluded, for instance, that a more balanced runoff regime is favourable for hydropower production, although they recommend that each hydropower plant should be analysed separately. Conversely, we assessed C1 to be insensitive to climate change based on the analysis of changes in the mean annual cycle. Meyer et al. (2012), however, who focused on low flow events, detected a significant low flow vulnerability of catchments in this particular region. This underlines the importance of a clear focus and a tailored study setup when suggestions for adaptation measures are requested. As a last example, $\mathrm{C} 2$ encompasses areas in the Swiss Plateau where conflicts between the water use for agriculture, drinking water supply and ecological requirements might emerge in the future. With regard to seasonal and an- nual changes, this cluster is not as climate-sensitive as the alpine clusters are, but the projected runoff still considerably decreases in late spring and summer when water demand by the concurrent users is usually highest.

\subsection{Sources of uncertainty}

We assume that the primary source of uncertainty associated with hydrological climate-impact modelling comes from climate models, which had been demonstrated by e.g. Arnell (2011), Kay et al. (2009), Teutschbein and Seibert (2010) and Wilby and Harris (2006). By applying ten different combinations of GCM-RCMs, we accounted for a spread in the hydrological projections caused by the climate models and omitted the other uncertainty sources mentioned in the introductory part to direct our efforts towards assessing as many different catchment types as possible instead.

The climate scenarios in our study do not include changes in the frequency and intensity of the climate variables, though, because they were derived with the delta change approach which only accounts for changes in the mean annual cycle of temperature and precipitation. This is a drawback, of course, with respect to the assessment of extremes (that we did not aim at). On the other hand, these rather moderate scenarios might constitute an advantage with respect to the validity of the model parameters: Vaze et al. (2010) showed, for instance, that model parameters can yield reasonable results if applied in impact studies with rather moderate precipitation changes, which is true for our climate scenarios.

Nevertheless, the calibrated model parameters are the crucial source of uncertainty associated with the hydrological model. As Merz et al. (2011) elaborated, calibrated model parameters are only valid for the period they were calibrated for, and "[...] care needs to be taken when using calibrated parameters for predictions of the future". They refer to the stationarity problem, here, which is related to hydrological model parameters. We assume, however, that the employed regionalization procedure might mitigate the adverse effects of stationary model parameters: the simulated hydrograph is virtually detached from one distinct set of model parameters. In other words, the seven different parameter sets that were applied to regionalize the runoff reflect model parameter uncertainty.

The land use is treated as a static catchment property in our study, although one can argue that land use will change under a changing climate and will impact on the hydrological response itself, which is likely to be true. The land use being a static catchment property in our model is therefore a rough simplification, which is why the effects of climateinduced changes in land use, e.g. an increase in tree line or an extended growing season, are foci of another study (Köplin et al., 2012).

The results of the cluster analysis depict only one possible grouping of the study catchments, because there is no distinct objective solution in catchment classification (Leyer and 
Wesche, 2007). In fact, the borders between the catchments are most likely less sharp, as they seem to be in the spatial visualization in Fig. 3. Nevertheless, the clustering seems to be robust because the catchments are similarly clustered in the RDA that was run independently from the cluster analysis.

The results of the RDA, on the other hand, certainly strongly depend on the set of constraints applied, and we may have missed other, possibly more important constraining variables. One can also argue that the catchment properties we chose are not characteristic for the clusters, which can be assumed from the substantial within-cluster spread of some variables depicted in Fig. 4. The comparatively high values for $R_{\text {adj }}^{2}$ indicate, however, that we captured a significant amount of variance explained through the constraints.

\subsection{Further research}

We showed just one possibility to reduce the workload in hydrological climate-impact studies, and there are several options to widen or modify our analysis. The cluster analysis could be tested for its robustness, for example, by separately clustering the hydro-climatological change signals of each climate scenario and comparing the results to the clustering based on the ensemble mean that we applied here. Moreover, different clustering methods could be tested, e.g. a fuzzy clustering that would account for smooth transitions between the clusters. An option to widen our study is to select a sample of catchments according to the suggestions mentioned above and consider additional uncertainty sources like, for instance, different hydrological models or calibrated parameter sets. Moreover, it would be interesting to apply the proposed procedure to all catchments but driven by climate scenarios that account for frequency and intensity changes, too, and compare the results to our findings. Presumably, we extracted essential components of hydrological change in Switzerland because we applied the basic changes in the annual cycles of temperature and precipitation. There might be other processes, though, that emerge with frequency and intensity changes of the climate variables that would be important for the assessment of extremes, for example.

A different approach to assess hydrological change would be to test a range of plausible changes in climate (derived from climate models) for their threshold exceedance of safety margins, for example (Prudhomme et al., 2010; van Pelt and Swart, 2011; Wetterhall et al., 2011). That is, this is a sensitivity analysis of a hydrological system to different climate changes rather than an impact analysis of climate change on hydrology. This approach has only recently gained attention for use in adaptation strategies (van Pelt and Swart, 2011) and offers an addition to the top-down approach applied in this study. However, it is not a substitute for climate impact studies, as it cannot account for the complete storyline of climate change that an ensemble of GCM-RCMs depicts.

It has to be stated that our findings are only valid for the study domain considered, but they are likely to be valid for other alpine regions in Europe, as well. Moreover, the proposed procedure is applicable to any desired study region and helps to understand and structure the hydrological change in the particular area of interest.

Acknowledgements. This study is funded by the Swiss Federal Office for the Environment (FOEN) in the framework of the joint research project "Climate Change in Switzerland - Hydrology" (CCHydro). The authors would like to thank the FOEN, the Swiss Federal Statistical Office (SFSO) and the Federal Office for Meteorology and Climatology (MeteoSwiss) for providing the necessary input data. The delta change scenario data were distributed by the Center for Climate Systems Modeling (C2SM). The data were derived from regional climate simulations of the EU FP6 Integrated Project ENSEMBLES (Contract number 505539) whose support is gratefully acknowledged. The dataset has been prepared by Thomas Bosshard at ETH Zurich, partly funded by swisselectric/Swiss Federal Office of Energy (SFOE) and $\mathrm{CCHydro/Swiss} \mathrm{Federal} \mathrm{Office} \mathrm{for} \mathrm{the} \mathrm{Environment} \mathrm{(FOEN).} \mathrm{The}$ authors would like to thank Frank Paul and Andreas Linsbauer, Institute of Geography, University of Zurich (GIUZ), for providing the scenarios of glacier retreat.

Edited by: E. Zehe

\section{References}

Ali, G., Tetzlaff, D., Soulsby, C., and McDonnell, J. J.: Topographic, pedologic and climatic interactions influencing streamflow generation at multiple catchment scales, Hydrol. Process., 17 pp., doi:10.1002/hyp.8416, 2011.

Arnell, N. W.: Uncertainty in the relationship between climate forcing and hydrological response in UK catchments, Hydrol. Earth Syst. Sci., 15, 897-912, doi:10.5194/hess-15-897-2011, 2011.

Bergström, S., Carlsson, B., Gardelin, M., Lindström, G., Petterson, A., and Rummukainen, M.: Climate change impacts on runoff in Sweden - assessments by global climate models, dynamical downscaling and hydrological modelling, Clim. Res., 16, 101112, 2001.

Birsan, M.-V., Molnar, P., Burlando, P., and Pfaundler, M.: Streamflow trends in Switzerland, J. Hydrol., 314, 312-329, doi:10.1016/j.jhydrol.2005.06.008, 2005.

Borcard, D., Gillet, F., and Legendre, P.: Numerical Ecology with R, Springer New York, New York, NY, 2011.

Bosshard, T., Kotlarski, S., Ewen, T., and Schär, C.: Spectral representation of the annual cycle in the climate change signal, Hydrol. Earth Syst. Sci., 15, 2777-2788, doi:10.5194/hess-15-27772011, 2011.

Bower, D., Hannah, D. M., and McGregor, G. R.: Techniques for assessing the climatic sensitivity of river flow regimes, Hydrol. Process., 18, 2515-2543, doi:10.1002/hyp.1479, 2004.

CH2011: Swiss Climate Change Scenarios CH2011, C2SM, MeteoSwiss, ETH, NCCR Climate, and OcCC, Zürich, Switzerland, 88 pp., 2011.

Christensen, N. S. and Lettenmaier, D. P.: A multimodel ensemble approach to assessment of climate change impacts on the hydrology and water resources of the Colorado River Basin, 
Hydrol. Earth Syst. Sci., 11, 1417-1434, doi:10.5194/hess-111417-2007, 2007.

Dankers, R. and Middelkoop, H.: River discharge and freshwater runoff to the Barents Sea under present and future climate conditions, Climatic Change, 87, 131-153, doi:10.1007/s10584-0079349-x, 2008.

Finger, D. C., Heinrich, G., Gobiet, A., and Bauder, A.: Projections of future water resources and their uncertainty in a glacierized catchment in the Swiss Alps and the subsequent effects on hydropower production during the 21 st century, Water Resour. Res., 48, W02521, doi:10.1029/2011WR010733, 2012.

FOEN: Observed Discharge Time Series of Swiss Rivers, Federal Office for the Environment FOEN, Berne, Switzerland, 2008.

FOEN: Strategie der Schweiz zur Anpassung an die Klimaänderung. Zwischenbericht zuhanden des Bundesrats, Federal Office for the Environment FOEN (Bundesamt für Umwelt BAFU), Berne, Switzerland, Report, 12 pp., http://www. bafu.admin.ch/klimaanpassung/11529/index.html?lang=de, last access: July 2012, 2010.

FOEN: Auswirkungen der Klimaänderung auf Wasserressourcen und Gewässer. Synthesebericht zum Projekt "Klimaänderung und Hydrologie in der Schweiz" (CCHydro), Bundesamt für Umwelt (Federal Office for the Environment), Bern, UmweltWissen Nr. 1217, 76 pp., 2012.

Gobena, A. K. and Gan, T. Y.: Low-frequency variability in Southwestern Canadian stream flow: links with largescale climate anomalies, Int. J. Climatol., 26, 1843-1869, doi:10.1002/joc.1336, 2006.

Graham, L. P., Andréasson, J., and Carlsson, B.: Assessing climate change impacts on hydrology from an ensemble of regional climate models, model scales and linking methods - a case study on the Lule River basin, Climatic Change, 81, 293307, doi:10.1007/s10584-006-9215-2, 2007.

Hamlet, A. F.: Assessing water resources adaptive capacity to climate change impacts in the Pacific Northwest Region of North America, Hydrol. Earth Syst. Sci., 15, 1427-1443, doi:10.5194/hess-15-1427-2011, 2011.

Hänggi, P.: Auswirkungen der hydroklimatischen Variabilität auf die Wasserkraftnutzung in der Schweiz, Berne, Switzerland, PhD Thesis, 206 pp., 2011.

Hänggi, P. and Weingartner, R.: Variations in Discharge Volumes for Hydropower Generation in Switzerland, Water Resour. Manag., 26, 1231-1252, doi:10.1007/s11269-011-9956-1, 2012.

Hannah, D. M., Kansakar, S. R., Gerrard, A., and Rees, G.: Flow regimes of Himalayan rivers of Nepal: nature and spatial patterns, J. Hydrol., 308, 18-32, doi:10.1016/j.jhydrol.2004.10.018, 2005.

Huss, M., Farinotti, D., Bauder, A., and Funk, M.: Modelling runoff from highly glacierized alpine drainage basins in a changing climate, Hydrol. Process., 22, 3888-3902, doi:10.1002/hyp.7055, 2008

Jasper, K., Calanca, P., Gyalistras, D., and Fuhrer, J.: Differential impacts of climate change on the hydrology of two alpine river basins, Climatic Change, 26, 113-129, 2004.

Kay, A. L., Davies, H. N., Bell, V. A., and Jones, R. G.: Comparison of uncertainty sources for climate change impacts: flood frequency in England, Climatic Change, 92, 41-63, doi:10.1007/s10584-008-9471-4, 2009.
Kingston, D. G., Hannah, D. M., Lawler, D. M., and McGregor, G. R.: Regional classification, variability, and trends of northern North Atlantic river flow, Hydrol. Process., 25, 1021-1033, doi:10.1002/hyp.7655, 2011.

Köplin, N., Viviroli, D., Schädler, B., and Weingartner, R.: How does climate change affect mesoscale catchments in Switzerland? - a framework for a comprehensive assessment, Adv. Geosci., 27, 111-119, doi:10.5194/adgeo-27-111-2010, 2010.

Köplin, N., Schädler, B., Viviroli, D., and Weingartner, R.: The importance of glacier and forest change in hydrological climateimpact studies, Hydrol. Earth Syst. Sci. Discuss., 9, 5983-6021, doi:10.5194/hessd-9-5983-2012, 2012.

Kunstmann, H., Schneider, K., Forkel, R., and Knoche, R.: Impact analysis of climate change for an Alpine catchment using high resolution dynamic downscaling of ECHAM4 time slices, Hydrol. Earth Syst. Sci., 8, 1031-1045, doi:10.5194/hess-8-10312004, 2004.

Legendre, P. and Legendre, L.: Numerical ecology, 2nd English edition, Elsevier, Amsterdam, 853 pp., 1998.

Legendre, P., Oksanen, J., and ter Braak, C. J. F.: Testing the significance of canonical axes in redundancy analysis, Methods in Ecology and Evolution, 2, 269-277, doi:10.1111/j.2041210X.2010.00078.x, 2011.

Ley, R., Casper, M. C., Hellebrand, H., and Merz, R.: Catchment classification by runoff behaviour with self-organizing maps (SOM), Hydrol. Earth Syst. Sci., 15, 2947-2962, doi:10.5194/hess-15-2947-2011, 2011.

Leyer, I. and Wesche, K.: Multivariate Statistik in der Ökologie, Eine Einführung, Springer, Berlin, Heidelberg, New York, 221 pp., 2007.

Linsbauer, A., Paul, F., Machguth, H., and Haeberli, W.: Comparing different methods to model scenarios of future glacier change for the entire Swiss Alps, Ann. Glaciol., submitted, 2012.

Merz, R., Parajka, J., and Blöschl, G.: Time stability of catchment model parameters: Implications for climate impact analyses, Water Resour. Res., 47, W02531, doi:10.1029/2010WR009505, 2011.

MeteoSwiss: Time Series of Meteorological Variables, Federal Office for Meteorology and Climatology, Zürich, Switzerland, 2008.

Meyer, R., Schädler, B., Viviroli, D., and Weingartner, R.: The implications of projected climate change on summer low flow in the Swiss Plateau, Hydrolog. Sci. J., submitted, 2012.

Nijssen, B., O’Donnell, G. M., Hamlet, A. F., and Lettenmaier, D. P.: Hydrologic sensitivity of global rivers to climate change, 50, 143-175, doi:10.1023/A:1010616428763, 2001.

Oksanen, J., Blanchet, G. F., Kindt, R., Legendre, P., Minchin, P. R., O'Hara, R. B., Simpson, G. L., Solymos, P., Stevens, M. H. H., and Wagner, H.: vegan: Community Ecology Package, version 2.0-2, http://cran.r-project.org/web/packages/vegan/ index.html, last access: February 2012, 2011.

Paul, F., Maisch, M., Rothenbühler, C., Hoelzle, M., and Haeberli, W.: Calculation and visualisation of future glacier extent in the Swiss Alps by means of hypsographic modelling, Global Planet. Change, 55, 343-357, doi:10.1016/j.gloplacha.2006.08.003, 2007.

Prudhomme, C., Wilby, R., Crooks, S., Kay, A., and Reynard, N.: Scenario-neutral approach to climate change impact studies: Application to flood risk, J. Hydrol., 390, 198-209, 
doi:10.1016/j.jhydrol.2010.06.043, 2010.

R Development Core Team: R: A language and environment for statistical computing, $\mathrm{R}$ version 2.14.1, R Foundation for Statistical Computing, Vienna, Austria, ISBN: 3-900051-07-0, http: //www.R-project.org/, last access: February 2012, 2011.

Renner, M. and Bernhofer, C.: Long term variability of the annual hydrological regime and sensitivity to temperature phase shifts in Saxony/Germany, Hydrol. Earth Syst. Sci., 15, 1819-1833, doi:10.5194/hess-15-1819-2011, 2011.

Sawicz, K., Wagener, T., Sivapalan, M., Troch, P. A., and Carrillo, G.: Catchment classification: empirical analysis of hydrologic similarity based on catchment function in the eastern USA, Hydrol. Earth Syst. Sci., 15, 2895-2911, doi:10.5194/hess-15-28952011, 2011.

Schaefli, B., Hingray, B., and Musy, A.: Climate change and hydropower production in the Swiss Alps: quantification of potential impacts and related modelling uncertainties, Hydrol. Earth Syst. Sci., 11, 1191-1205, doi:10.5194/hess-11-11912007, 2007.

SFSO: GEOSTAT Database Products. Licence No. G158000315, $\left.{ }^{(}\right)$SFSO, Swiss Federal Statistical Office, Neuchâtel, Switzerland, 2003.

Teutschbein, C. and Seibert, J.: Regional Climate Models for Hydrological Impact Studies at the Catchment Scale: A Review of Recent Modeling Strategies, 4, 834-860, doi:10.1111/j.17498198.2010.00357.x, 2010.

UNFCCC: Report of the Conference of the Parties on its thirteenth session, held in Bali from 3 to 15 December 2007. Part Two: Action taken by the Conference of the Parties at its thirteenth session, United Nations Framework Convention on Climate Change, Report, 60 pp., http://unfccc.int/resource/docs/2007/cop13/eng/ 06a01.pdf, last access: February 2012, 2008.

van der Linden, P. and Mitchell, J.: ENSEMBLES: Climate Change and its Impacts: Summary of research and results from the ENSEMBLES project, FitzRoy Road, Exeter EX1 3PB, UK, 160 pp., 2009.

van Pelt, S. C. and Swart, R. J.: Climate Change Risk Management in Transnational River Basins: The Rhine, Water Resour. Manage., 25, 3837-3861, doi:10.1007/s11269-011-9891-1, 2011.

Vaze, J., Post, D., Chiew, F., Perraud, J.-M., Viney, N., and Teng, J.: Climate non-stationarity - Validity of calibrated rainfall-runoff models for use in climate change studies, J. Hydrol., 394, 447457, doi:10.1016/j.jhydrol.2010.09.018, 2010.

Viviroli, D. and Weingartner, R.: Umfassende hochwasserhydrologische Beurteilung ungemessener mesoskaliger Einzugsgebiete im schweizerischen Rheineinzugsgebiet durch prozessorientierte Modellierung, Comprehensive flood-hydrological assessment of ungauged catchments in the Swiss part of the River Rhine basin by means of process-oriented modelling, Hydrol. Wasserbewirts., 55, 258-272, 2011.
Viviroli, D., Zappa, M., Gurtz, J., and Weingartner, R.: An introduction to the hydrological modelling system PREVAH and its preand post-processing-tools, Environ. Modell. Softw., 24, 12091222, doi:10.1016/j.envsoft.2009.04.001, 2009a.

Viviroli, D., Zappa, M., Schwanbeck, J., Gurtz, J., and Weingartner, R.: Continuous simulation for flood estimation in ungauged mesoscale catchments of Switzerland - Part I: Modelling framework and calibration results, J. Hydrol., 377, 191207, doi:10.1016/j.jhydrol.2009.08.023, 2009b.

Viviroli, D., Mittelbach, H., Gurtz, J., and Weingartner, R.: Continuous simulation for flood estimation in ungauged mesoscale catchments of Switzerland - Part II: Parameter regionalisation and flood estimation results, J. Hydrol., 377, 208-225, doi:10.1016/j.jhydrol.2009.08.022, 2009c.

Viviroli, D., Archer, D. R., Buytaert, W., Fowler, H. J., Greenwood, G. B., Hamlet, A. F., Huang, Y., Koboltschnig, G., Litaor, M. I., López-Moreno, J. I., Lorentz, S., Schädler, B., Schreier, H., Schwaiger, K., Vuille, M., and Woods, R.: Climate change and mountain water resources: overview and recommendations for research, management and policy, Hydrol. Earth Syst. Sci., 15, 471-504, doi:10.5194/hess-15-471-2011, 2011.

Volken, D.: Projektbericht. CCHydro - Auswirkungen der Klimaänderung auf die Wasserressourcen und die Gewässer in der Schweiz, CCHydro - impacts of climate change on water resources, rivers, and lakes in Switzerland, Hydrol. Wasserbewirts., 54, 143-146, 2010.

Wagener, T., Sivapalan, M., Troch, P., and Woods, R.: Catchment Classification and Hydrologic Similarity, Geography Compass, 1, 901-931, doi:10.1111/j.1749-8198.2007.00039.x, 2007.

Weingartner, R.: Regionalhydrologische Analysen. Grundlagen und Anwendungen, in: Beiträge zur Hydrologie der Schweiz, 37, Schweizerische Gesellschaft für Hydrologie und Limnologie (SGHL), Berne, Switzerland, 178 pp., http://chy.scnatweb.ch/ downloads/Nr.37_001.pdf, last access: February 2012, 1999.

Wetterhall, F., Graham, L. P., Andréasson, J., Rosberg, J., and Yang, W.: Using ensemble climate projections to assess probabilistic hydrological change in the Nordic region, Nat. Hazards Earth Syst. Sci., 11, 2295-2306, doi:10.5194/nhess-11-22952011, 2011.

Wilby, R. L. and Harris, I.: A framework for assessing uncertainties in climate change impacts: Low-flow scenarios for the River Thames, UK, Water Resour. Res., 42, W02419, doi:10.1029/2005WR004065, 2006. 